\title{
Effect of Instant Controlled Pressure Drop Process Coupled to Drying and Freezing on Antioxidant Activity of Green "Poblano” Pepper (Capsicum annuum L.)
}

\author{
Carmen Téllez-Pérez ${ }^{1,3}$, Anaberta Cardador-Martínez ${ }^{1}$, Sabah Mounir ${ }^{2}$, \\ José Gerardo Montejano-Gaitán ${ }^{1}$, Vaclav Sobolik ${ }^{3}$, Karim Allaf ${ }^{3 *}$ \\ ${ }^{1}$ Tecnológico de Monterrey-Escuela en Ingeniería, Biotecnología y Agronomía, Querétaro, México; ${ }^{2}$ Department of Food Science, \\ Faculty of Agriculture, Zagazig University, Zagazig, Egypt; ${ }^{3}$ LaSIE FRE 3474 CNRS, Laboratory Engineering Science for Environ- \\ ment, University of La Rochelle, La Rochelle, France. \\ Email: *kallaf@univ-lr.fr
}

Received January $23^{\text {rd }}, 2013$; revised February $23^{\text {rd }}, 2013$; accepted March $3^{\text {rd }}, 2013$

\begin{abstract}
Different food operations have been intensified through assisting them by instant controlled pressure drop DIC treatment. Such processes should be defined in order to preserve the main nutritional and sensorial contents of the raw material. The present paper is dedicated to study the evolution of the main bioactive compounds (total phenolics and flavonoids) and functional properties such as the antioxidant activity of processed samples in the case of Green "Poblano" Pepper (Capsicum annuum L.). Results issued from DIC-assisted hot air drying, and DIC-assisted freezing, allowed to identifying the impact of DIC studied operating parameters, which were the saturated steam pressure and the processing time, and the best DIC treatment correlated with the considered operation.
\end{abstract}

Keywords: Instant Controlled Pressure Drop; Capsicum; Phenols; Flavonoids; Antioxidant Activity; Drying; Freezing

\section{Introduction}

Pepper is derived from a Greek word originally used for black and white pepper, but subsequently applied to genera belonging to seven different families, all of which have pungent fruits or seeds. "Chilli" comes from one of the indigenous languages of Mexico, where Capsicum has been consumed for more than 5000 years. The bell peppers, paprikas and pimientos, together with most of the Mexican chillies, are all included in C. annuum. This is now the most widespread and economically important cultivated species of all the Capsicum [1].

The pepper (Capsicum annuum, L.) is highly appreciated for its flavor, color, pungency, taste, aroma, and for its physiological and pharmaceutical uses [2]. Pepper is an excellent source of phytochemicals and essential nutrients such as ascorbic acid, capsaicinoids, flavonoids, phenolic compounds, carotenoids, etc. [3]. Recent researches have shown that dietary capsaicin is effective in reducing oxidant stress, rheumatism, arthritis, neuralgia, lumbago, cancer and diabetes among other diseases [4-6]. Hence, it is very important to study food processing techniques in terms of their ability to preserve the natural bioactive molecules of pepper.

\footnotetext{
"Corresponding author.
}

Thermal treatments of a food systematically induce physical changes and chemical reactions, which in turn affect its sensory characteristics and nutritional value, either advantageously or adversely [7,8]. Antioxidants, well-known for their health properties related to the prevention of degenerative diseases are damaged by long thermal treatments [9-12].

Drying is one of the oldest and most effective means of preserving foods. However, some studies have shown that long periods of heating cause losses of sensorial (texture, taste, flavor, and color) and nutritional quality $[9,13]$, such as reduction of ascorbic acid content [14]. Comparatively during the freezing process ice crystals can also cause physical, structural, chemical and nutritional damage $[15,16]$.

Dehydrofreezing is a new food processing of partial dehydration prior to freezing. It has shown advantages on texture properties and energy consumption, due to the effect of diminishing the tissue damage by removing part of water from vegetable tissue prior to freezing $[15,16]$.

Instant Controlled Pressure Drop process, well known by the French acronym "DIC" (Détente Instantanée Contrôlée), is based on the thermo-mechanical effects induced by subjecting the raw material for a short period of time to saturated steam (about $0.1-0.6 \mathrm{MPa}$ according to 
the product), followed by an abrupt pressure drop towards a vacuum (about $5 \mathrm{kPa}$ ). This abrupt pressure drop $(\Delta \mathrm{P} / \Delta \mathrm{t}>0.5 \mathrm{MPa} / \mathrm{s})$ triggers simultaneously autovaporization of volatile compounds, swelling, possibly rupturing some cell walls and instantaneously cooling the products, which stops thermal degradation $[17,18]$.

The aim of the present study was to evaluate and compare the effects of traditional methods of drying and freezing to the DIC process coupled to drying and freezing, on the phytochemical content (phenols and flavonoids) and the antioxidant activity of Green Poblano Pepper.

\section{Materials and Methods}

\subsection{Materials}

\subsubsection{Chemicals}

Folin-Ciocalteau reagent 2N, 2-Aminoethyl diphenyl borate 98\%, 2,2-Diphenyl-1-picrylhydrazil (DPPH ), Gallic acid, 2,2-azinobis (3-ethylbenzothiazolin) 6-sulfonic acid (ABTS), ( \pm )-6-Hydroxy-2,5,7,8-tetramethylchromane-2carboxylic acid (Trolox), Rutin hydrate $\geq 94 \%$ (HPLC) powder, were obtained from sigma. All other reagents and chemicals of analytical grade were procured from local sources and milli-Q water was used.

\subsubsection{Samples}

Physiologically ripe Green Poblano Pepper was bought at local market in Querétaro, Mexico on December 2010 and was transported to the laboratory.

\subsection{Processing Methods}

Before any treatments, good quality peppers (absence of mold and insect contamination) were manually selected and washed. From whole washed fruit the peduncles, seeds, capsaicin glands, and placenta, were eliminated. The pericarp was manually diced to an average thickness of $8 \mathrm{~mm}$.

The comparative study of traditional methods of drying and freezing with the DIC process, was carried out as shown on Figure 1. Fresh diced Poblano Peppers were divided into three parts, 1) Raw Material (RM); 2) Drying and 3) Traditional Freezing (TF). The RM was stored for two days at $4^{\circ} \mathrm{C}$ until analysis.

Dehydration involved two different methods, hot air drying and freeze drying (FD).

Hot air drying of Peppers was applied at $60^{\circ} \mathrm{C}, 265 \mathrm{~Pa}$ as partial pressure of vapor and $1.2 \mathrm{~m} \cdot \mathrm{s}^{-1}$ of air flux. Drying was carried out until 5\% d.b (dry basis) and samples were identified as Total Hot Air Drying (THAD).

Freeze drying (FD) stated by 3-min liquid nitrogen freezing, followed by a sublimation stage at $-20^{\circ} \mathrm{C}, 0.66$ $\mathrm{Pa}$ for $12 \mathrm{~h}$ and a desorption stage at $25^{\circ} \mathrm{C}, 0.66 \mathrm{~Pa}$ for 12 $\mathrm{h}$; both stages were carried out in a standard freeze drier

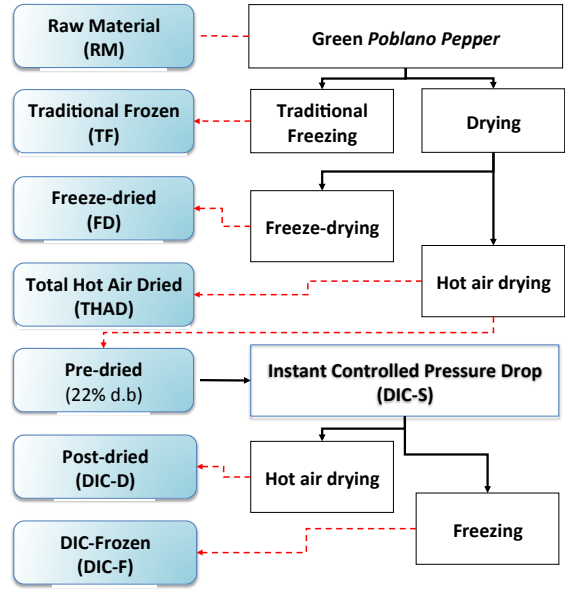

Figure 1. Schematic diagram of processing of green poblano pepper by dehydration and freezing methods.

(Virtis FM 6.6ES 374330, USA).

\subsubsection{Instant Controlled Pressure Drop DIC Treatment}

The DIC equipment LABIC0.1 (ABCAR-DIC Process; La Rochelle; France) consisted of three major components; first a double jacket processing vessel 1) where samples were setting and treating, different conditions of saturated steam pressure and a vacuum were provided; second, a vacuum system, which consisted mainly of a vacuum tank 2) and a water ring vacuum pump 3 ) and third the decompression system through an instant butterfly valve connecting/separating the processing and the vacuum tank 2). Saturated steam (F1) was supplied into the processing vessel, through the valve (V1). The double jacket was heated by saturated steam (F2). The reactor was equipped by a vent (V3). The vacuum tank was cooled by tap water (F3) circulating in the double jacket. Manometers and pressure sensors showed the vessel and tank pressures. Condensates were removed from the reservoir through the trap 4) with a system of valves (V4, V5 and V6) [19]. Figure 2 shows the schematic diagram of DIC equipment reactor LABIC0.1.

For the DIC treatment of peppers, samples were enclosed in a perforated stainless steel container and set in the reactor 1) at the atmospheric pressure and then this was closed. By opening the valve (V2) an initial vacuum was performed. After closing (V2), saturated steam was injected into the reactor by the valve (V1); injection was upheld manually during the given treatment time, and it was afterward closed. The abrupt pressure drop towards a vacuum was carried out by an abrupt opening $(<0.5 \mathrm{~s})$ of the valve (V2). This abrupt pressure drop triggered an adiabatic auto-vaporization of superheated liquid contained in the material, instantaneously cooling the structure, and swelling and even rupturing the cell walls as 




Figure 2. Schematic diagram of DIC Equipment LABIC0.1 (ABCAR-DIC Process; La Rochelle; France): (1) DIC Reactor; (2) Vacuum tank; (3) Vacuum pump; (4) Trap, V1V7-valves, F1 and F2-saturated steam injection, F3-cooling water, P-Pressure gauge and T-thermocouples.

well. Finally, atmospheric pressure was restored in the autoclave by the vent (V3) and the material was recovered. The pressure in the vacuum tank 2) was almost constant and equal to $5 \mathrm{kPa}$.

Instant Controlled Pressure Drop process (DIC) included two main steps (Figure 3) of heating and pressure drop.

1) Pre-dried peppers (22\% d.b) were introduced on the DIC processing reactor LABIC0.1 (ABCAR-DIC Process; La Rochelle, France). Afterward a vacuum of $3 \mathrm{kPa}$ was established (Figure 3A). The initial vacuum was carried out to facilitate and mediate the close exchange between the incoming steam and the product surface. Saturated steam was injected into the reactor at a fixed pressure level $(\mathrm{P})$ ranged from 0.15 and $0.45 \mathrm{MPa}$ (Figure 3B). Once tested pressure was reached, this was maintained for a given thermal treatment time " $\mathrm{t}$ " ranged between 20 and $60 \mathrm{~s}$ (Figure 3C). Operating parameters of "P" and " $\mathrm{t}$ " were selected as shown in experimental design section.

2) Once treatment time finished, samples were subjected to an Instant controlled pressure drop $(\Delta \mathrm{P} / \Delta \mathrm{t}>0.5$ $\mathrm{MPa} \cdot \mathrm{s}^{-1}$ ) towards vacuum of $5 \mathrm{kPa}$ (Figure 3D).

After a vacuum stage period time, pressure was released toward the atmospheric pressure (Figure 3E) and samples were removed from the reactor. Obtained samples just after DIC treatment were called DIC-Swelling (DIC-S).

DIC-S samples were divided in two preserving methods. One part consisted to a second drying stage at the same conditions of THAD to obtain DIC-Dried products

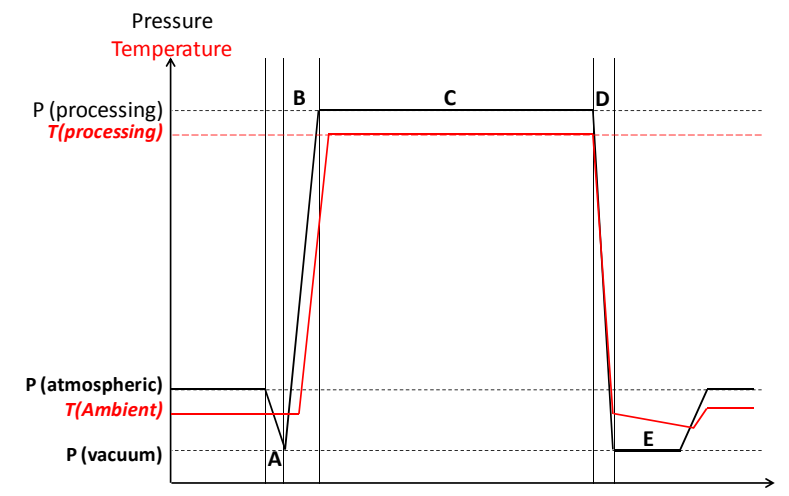

Figure 3. Schematic time-pressure profiles of a DIC processing cycle. A: establishment of the vacuum; B: injection of steam; C: maintain of treatment pressure during selected time; D: instant controlled pressure drop towards vacuum and E: establishment of the atmospheric pressure.

(DIC-D) and the other part consisted to a freezing $\left(-20^{\circ} \mathrm{C}\right)$ to obtain DIC-Frozen products (DIC-F). To compare the impact of DIC treatment of both preserving methods, one part of DIC-S samples was also studied (stored at $4^{\circ} \mathrm{C}$ ).

\subsubsection{Freezing Methods}

Traditional Freezing (TF) was applied on fresh pepper under $-20^{\circ} \mathrm{C}$. Experiments were carried out in a chest freezer (Frigidaire Gallery, GLFC1326FW, USA).

\subsection{Assessment Methods}

\subsubsection{Proximal Analysis}

The water content (method 925.10), the crude protein content (Kjeldahl method 981.10, conversion factor of 6.25 ) and the amount of ashes (method 923.03) were evaluated through AOAC Official method [20]; the lipid content by the Goldfish method [21], the crude fiber by the Crude Fiber Analysis in Feeds by Filter Bag Technique (AOCS method). The carbohydrates were calculated by difference on $100 \mathrm{~g}$ of fresh sample as basis.

\subsubsection{Antioxidant Extraction}

Before extraction, $10 \mathrm{~g}$ of each various pepper samples; RM, FD, TF, THAD, DIC-S, DIC-D and DIC-F were milled and homogenized in a high-speed blender $(40 \mathrm{~s})$ and moisture content was measured (AOAC method) [20]. Samples $(0.5 \mathrm{~g})$ were extracted with $10 \mathrm{~mL}$ of $\mathrm{MeOH}: \mathrm{HCl}(99: 1, \% \mathrm{v} / \mathrm{v}), 2 \mathrm{~h}$ in the dark, using an orbital shaker operated at $200 \mathrm{rpm}$ at room temperature, and centrifuged at $6000 \mathrm{rpm}$ for $20 \mathrm{~min}$. The extraction solutions were filtered through Whatman No. 4 filter paper and stored in the dark at $-20^{\circ} \mathrm{C}$ until analysis [22]. For each sample duplicate extraction and analysis were carried out. 


\subsubsection{Total Phenolic Content}

Total phenols content was estimated by usingFolin-Ciocalteau colorimetric method [23]. Briefly, $20 \mu \mathrm{L}$ of the extracts were diluted with $1.5 \mathrm{~mL}$ of Milli-Q water and oxidized with $0.1 \mathrm{~mL}$ of $0.5 \mathrm{~N}$ Folin-Ciocalteaureagent, after five minutes the reaction was neutralized with 0.3 $\mathrm{mL}$ sodium carbonate solution $(20 \%)$. The absorbance values were obtained by the resulting blue color measured at $760 \mathrm{~nm}$ with a spectrophotometer (UV-Vis Double Beam UVD-3500, Labomed, Inc. USA), after 2-h, $25^{\circ} \mathrm{C}$ incubation on darkness. Quantification was done on the basis of a standard curve of Gallic acid, concentration ranging from 0 to $500 \mu \mathrm{g} \cdot \mathrm{mL}^{-1}\left(\mathrm{r}^{2}=0.99\right)$. Results were expressed as $\mathrm{mg}$ of Gallic acid equivalent per grams of dry matter (mg Gallic acid eq/g d.b).

\subsubsection{Flavonoids Content}

The spectrophotometric assay for the quantitative determination of flavonoid content adapted for its use with microplates, was used [24]. Briefly, the method consisted of mixing $50 \mu \mathrm{L}$ of the methanolic extract with $150 \mu \mathrm{L}$ of distilled water and $50 \mu \mathrm{L}$ of a solution of $10 \mathrm{~g} \cdot \mathrm{L}^{-1}$ 2-aminoethyldiphenylborate in a 96-well microtitration flat-bottom plate. The absorbance of the solution was monitored at $404 \mathrm{~nm}$ after 15 min with a spectrophotometer (XMarkMicroplate Spectrophotometer Bio-Rad Laboratories, Japan). Extract absorption was compared with that of a rutin standard at concentrations ranging from 0 to $200 \mu \mathrm{g} \cdot \mathrm{mL}^{-1}\left(\mathrm{r}^{2}=0.99\right)$. Flavonoid content was expressed as mg rutin equivalent per gram of dry matter (mg rutin eq/g d.b).

\subsubsection{DPPH Scavenging Capacity}

2,2-Diphenyl-1-picrylhydrazil (DPPH) is a free radical used for assessing antioxidant activity. Reduction of DPPH by an antioxidant or by a radical species results in a loss of absorbance at $520 \mathrm{~nm}$. Determination of antioxidant capacity adapted for microplates was used [22]. Briefly, according to the results obtained of total phenol content, standards (Trolox) and samples were prepared at $500 \mu \mathrm{M}$ in methanol; then $20 \mu \mathrm{L}$ of extract or standard were mixed with $200 \mu \mathrm{L}$ of DPPH solution $(125 \mu \mathrm{M}$ in $80 \%$ methanol) on $96-w e l l$ flat-bottom visible light plate, samples were prepared in triplicate. The plate was then covered and left in the dark at room temperature $\left(20^{\circ} \mathrm{C}\right)$, after $90 \mathrm{~min}$, absorbance at $520 \mathrm{~nm}$ was measured in the microplate spectrophotometer. Data were expressed as a percentage of DPPH discoloration.

\subsubsection{Trolox Equivalent Antioxidant Capacity by ABTS}

The Trolox equivalent antioxidant capacity (TEAC) method is based on the ability of an antioxidant to scavenge the preformed radical cation ABTS relative to that of the standard antioxidant Trolox. The total antioxidant capacity of extracts was realized according to the improved ABTS method described by Re et al. [25], and adapted for its use in microplates. Briefly, ABTS radical cation was produced by reacting $7 \mathrm{mM}$ of 2,2'-azinobis (3ethylbenzothiazoline-6-sulfonic acid), diammonium salt (ABTS) and $2.45 \mathrm{mM}$ potassium persulfate after incubation at room temperature in dark for $16 \mathrm{~h}$. The stock solution of ABTS was diluted with ethanol just before use to an absorbance of $0.80 \pm 0.1$ at $734 \mathrm{~nm}$. Standards and samples prepared at $500 \mu \mathrm{M}$ in methanol were used. The $200 \mu \mathrm{L}$ of ABTS solution and the $20 \mu \mathrm{L}$ standard (Trolox) or sample solutions were added to the well on the visible light 96-microwell plate and mixed thoroughly. The absorbance readings were taken at $734 \mathrm{~nm}$ just 6 min after using a visible-UV microplate reader. Trolox standard concentrations range from 0 to $500 \mu \mathrm{M}$. TEAC of the sample was calculated as $\mu \mathrm{M}$ of Trolox needed to give the same degree of discoloration than the samples at 500 $\mu \mathrm{M}$.

\subsection{Experimental Design and Statistical Analysis for DIC Treatment}

A five-level central composite rotatable design was employed to evaluate the effect of the DIC operating parameters. After preliminary trials, the saturated steam pressure " $\mathrm{P}$ " $(\mathrm{MPa})$ and the processing heating time " $\mathrm{t}$ " $(\mathrm{s})$, were used as independent variables $(\mathrm{n}=2)$, ranged between $0.15-0.45 \mathrm{MPa}$ and $20-60 \mathrm{~s}$, respectively. The antioxidant activity and the total phenolic and flavonoid contents [26,27], were the considered responses (dependent variables). Thus, the studied design included $2^{\mathrm{n}}=2^{2}=4(-1 /-1 ;-1 /+1 ;+1 /-1$ and $+1 /+1)$ as factorial trials, $2 \times \mathrm{n}=2 \times 2=4(-\alpha / 0 ;+\alpha / 0 ; 0 /-\alpha$ and $0 /+\alpha)$ as star trials; and the central point $(0,0)$ was triplicated. The total trials were 11. The value of $\alpha$ (axial distance) depending on the number (n) of operating parameters was calculated as $\alpha=\sqrt[4]{2^{n}}=1.4142$. The operative DIC parameters applied are shown on Tables 1 and 2. Statgraphics Plus software (version XVI) was used for statistical analysis.

\section{Results}

\subsection{Physico-Chemicals Properties}

Proximate analysis of pepper (on $100 \mathrm{~g}$ of fresh weight)

Table 1. Coded and real levels of independent variables used in the experimental design. Axial distance $\alpha=1.4142$.

\begin{tabular}{cccccc}
\hline \multirow{2}{*}{ Factor } & \multicolumn{5}{c}{ Coded level } \\
\cline { 2 - 6 } & $-\alpha$ & -1 & 0 & 1 & $+\alpha$ \\
\hline Processing Pressure $(\mathrm{MPa})$ & 0.15 & 0.19 & 0.30 & 0.41 & 0.45 \\
Processing Time (s) & 20 & 26 & 40 & 54 & 60 \\
\hline
\end{tabular}


Antioxidant Activity of Green "Poblano" Pepper (Capsicum annuum L.)

Table 2. Run experimental values.

\begin{tabular}{cccccccccccccccc}
\hline Factor & \multicolumn{1}{c}{ DIC Treatment } \\
\cline { 2 - 9 } & 1 & 2 & 3 & 4 & 5 & 6 & 7 & 8 & 9 & 10 & 11 \\
\hline $\begin{array}{c}\text { Processing Pressure (MPa) } \\
\text { Processing Time (s) }\end{array}$ & 0.45 & 0.30 & 0.30 & 0.41 & 0.41 & 0.30 & 0.19 & 0.19 & 0.15 & 0.30 & 0.30 \\
\hline
\end{tabular}

presented an initial moisture content of $91.13 \pm 0.74 \mathrm{~g}$; crude protein (nitrogen $\times 6.25$ ) of $1.33 \pm 0.12 \mathrm{~g}$; total lipids of $0.11 \pm 0.001 \mathrm{~g}$; crude fiber of $1.07 \pm 0.02$; crude ash of $0.45 \pm 0.11 \mathrm{~g}$; available carbohydrates (by difference) of $5.91 \pm 0.99 \mathrm{~g}$. Obtained results were in accordance with those of green bell peppers [28], only small differences can be pointed out on the values obtained for green Poblano peppers, which showed slightly higher contents of protein, total carbohydrates, minerals and fiber, and lower amounts of moisture content and lipids, which can be attributed to differences in the varieties.

\subsection{Total Phenolic and Flavonoids Content of Dried and Frozen Poblano Pepper}

Most of the studies that evaluate the total phenol content of pepper focus on the differences among the varieties [29-32], the changes at different ripening stages fruit [33, $34]$ and on the impact of agricultural cultivation practices $[32,35]$; nevertheless little information exist about the impact of drying or frozen treatment conditions on the content of this bioactive molecules. Thus, this study focused on the impact of these preserving methods on the phytochemical content of Poblano Pepper. Tables $\mathbf{3}$ and 4 summarize these results.

Obtained results showed that Total Phenol Content (TPC) varied widely according to different drying and freezing conditions. In the case of FD samples, it was observed that compared to RM (24.55 mg Gallic acid equivalents/g d.b), it reduced the TPC on 5\%. Respect to Freezing, the traditional method (TF) showed the highest loss of TPC (30\%) respect to RM. On the other hand, an interesting good impact of DIC-assisted drying and freezing, on the total phenol content of peppers is shown (Table 4). In fact, DIC-S (Point 1), DIC-D (Point 3) and DIC-F (Point 4) increased the TPC of pepper compared to RM, being observed that under high values of the saturated steam pressure " $\mathrm{P}$ " and the holding time " $\mathrm{t}$ " of DIC treatment conditions, the TPC was increased. Specifically for DIC-D, as observed on Figure 4, the thermal holding time and the quadratic effect of this factor had a significant effect on increasing the TPC, meaning that the higher the holding time, the higher the TPC of dried samples.

Equation (1) is the adequate empirical regression model $\left(\mathrm{R}^{2}=90.73 \%\right)$ of the $\mathrm{TPC}_{\mathrm{DIC}-\mathrm{D}}$ :
Table 3. Total phenolic and flavonoids content of dried and frozen poblano pepper (values represent the mean of triplicates measures \pm the standard error).

\begin{tabular}{cccc}
\hline Process & $\begin{array}{c}\text { TPC } \\
\text { (mg Gallic acid eq/g d.b) }\end{array}$ & $\begin{array}{c}\text { TFC } \\
(\text { mg rutin eq/g d.b })\end{array}$ & $\begin{array}{c}\text { RFP } \\
(\%)\end{array}$ \\
\hline RM & $24.55 \pm 0.57$ & $11.86 \pm 0.37$ & $48.30 \pm 1.50$ \\
FD & $23.39 \pm 1.83$ & $14.27 \pm 0.52$ & $61.02 \pm 2.20$ \\
THAD & $24.67 \pm 0.80$ & $11.00 \pm 0.33$ & $44.58 \pm 1.33$ \\
TF & $17.17 \pm 1.45$ & $14.92 \pm 0.56$ & $86.89 \pm 3.28$ \\
\hline
\end{tabular}

$$
\begin{aligned}
\mathrm{TPC}_{\text {DIC-D }}= & -2.0053+36.49 \mathrm{P}+0.925 \mathrm{t} \\
& -124.91 \mathrm{P}^{2}+1.164 \mathrm{Pt}-0.0127 \mathrm{t}^{2}
\end{aligned}
$$

For DIC-S and DIC-F, under the selected range of DIC treatment conditions any of the factors, "P" and " $t$ ", presented significant effects on the TPC. Even so, these treatments showed higher values of TPC under P: 0.41 $\mathrm{MPa}$ and t: $54 \mathrm{~s}$, being these 29.72 and $33.62 \mathrm{mg}$ of Gallic acid equivalents/g d.b for DIC-S and DIC-F respectively. In fact, under these operating conditions the DIC$\mathrm{F}$ presented the best performance to preserve phenolic compounds, being 1.95 times better than TF and 1.36 times better than RM.

From Figure 5, it can be observed the impact of the THAD and the DIC-D treatments on the structure of dried Poblano peppers. THAD samples presented a collapsed structure, contrary the DIC-D samples presented a high porous structure.

Obtained results were quite relevant because contrary to most of the studies of thermal processapplied on peppers as drying [14], microwave heating, stir frying and boiling water [10] that shows important reductions of TPC respect to RM, the DIC process as a high temperature and short time treatment allowed to optimize the TPC, showing that degradation of polyphenols are related not only to applied temperature, but also to processing time.

Regarding the Total Flavonoids Content (TFC) of Poblano Pepper some studies have shown that it contains important quantities of flavonoids [33,34,36-38], however it has been showed that they are quite affected by food preparation and processing, decreasing their content by $50 \%$ in some cases [39].

At this respect, this study showed that both of studied 
Table 4. Total phenol and flavonoids content of dried and frozen poblano pepper couple to DIC; Values represent the mean of triplicates \pm the standard error.

\begin{tabular}{|c|c|c|c|c|c|c|c|c|c|}
\hline \multirow{2}{*}{ DIC } & \multicolumn{3}{|c|}{$\begin{array}{l}\text { Total phenolic content TPC } \\
\text { (mg Gallic acid eq/g d.b) }\end{array}$} & \multicolumn{3}{|c|}{$\begin{array}{l}\text { Total Flavonoids content TFC } \\
\text { (mg rutin eq } / \mathrm{g} \text { d.b) }\end{array}$} & \multicolumn{3}{|c|}{$\begin{array}{l}\text { Ratio between the Flavonoids and } \\
\text { Phenolic compounds RFP (\%) }\end{array}$} \\
\hline & DIC-Swelling & DIC-Dried & DIC-Frozen & DIC-Swelling & DIC-Dried & DIC-Frozen & DIC-Swelling & DIC-Dried & DIC-Frozen \\
\hline 1 & $29.72 \pm 1.54$ & $27.15 \pm 0.29$ & $27.79 \pm 1.36$ & $15.19 \pm 0.26$ & $10.42 \pm 0.39$ & $11.79 \pm 0.88$ & $51.09 \pm 0.89$ & $38.38 \pm 1.44$ & $42.42 \pm 3.16$ \\
\hline 2 & $21.94 \pm 0.82$ & $28.98 \pm 2.12$ & $29.50 \pm 2.05$ & $11.82 \pm 0.29$ & $9.90 \pm 1.36$ & $15.57 \pm 0.40$ & $53.85 \pm 1.33$ & $34.18 \pm 4.69$ & $52.79 \pm 1.36$ \\
\hline 3 & $22.05 \pm 1.04$ & $30.39 \pm 1.47$ & $27.61 \pm 0.55$ & $13.87 \pm 0.56$ & $9.90 \pm 0.61$ & $11.86 \pm 0.42$ & $62.92 \pm 2.53$ & $32.59 \pm 2.02$ & $42.94 \pm 1.54$ \\
\hline 4 & $23.12 \pm 2.14$ & $29.61 \pm 0.69$ & $33.62 \pm 0.14$ & $13.24 \pm 0.98$ & $9.90 \pm 0.55$ & $15.10 \pm 0.77$ & $57.25 \pm 4.23$ & $33.43 \pm 1.86$ & $44.92 \pm 2.30$ \\
\hline 5 & $20.67 \pm 1.85$ & $20.19 \pm 0.43$ & $30.62 \pm 1.53$ & $12.94 \pm 0.34$ & $7.78 \pm 0.66$ & $14.96 \pm 0.82$ & $62.61 \pm 1.66$ & $38.56 \pm 3.29$ & $48.84 \pm 2.69$ \\
\hline 6 & $23.83 \pm 3.35$ & $28.20 \pm 0.26$ & $28.08 \pm 2.00$ & $12.33 \pm 0.45$ & $9.31 \pm 0.26$ & $14.69 \pm 0.51$ & $51.73 \pm 1.90$ & $33.01 \pm 0.92$ & $52.31 \pm 1.82$ \\
\hline 7 & $20.04 \pm 0.31$ & $23.34 \pm 0.66$ & $27.43 \pm 1.49$ & $11.01 \pm 0.14$ & $9.24 \pm 0.10$ & $13.65 \pm 0.49$ & $54.97 \pm 0.71$ & $39.57 \pm 0.44$ & $49.76 \pm 1.78$ \\
\hline 8 & $22.87 \pm 1.45$ & $25.60 \pm 0.43$ & $27.79 \pm 1.38$ & $12.20 \pm 0.50$ & $8.91 \pm 0.17$ & $14.45 \pm 1.03$ & $53.35 \pm 2.20$ & $34.82 \pm 0.66$ & $51.98 \pm 3.71$ \\
\hline 9 & $20.68 \pm 0.86$ & $22.70 \pm 0.39$ & $30.03 \pm 1.21$ & $12.07 \pm 0.27$ & $8.84 \pm 0.33$ & $14.52 \pm 1.56$ & $58.35 \pm 1.29$ & $38.92 \pm 1.46$ & $48.36 \pm 5.21$ \\
\hline 10 & $19.71 \pm 0.50$ & $16.94 \pm 0.98$ & $30.00 \pm 2.02$ & $10.51 \pm 0.09$ & $6.54 \pm 0.08$ & $15.97 \pm 0.61$ & $53.31 \pm 0.48$ & $38.64 \pm 0.47$ & $53.24 \pm 2.02$ \\
\hline 11 & $26.20 \pm 0.15$ & $26.37 \pm 0.31$ & $28.91 \pm 0.50$ & $12.42 \pm 0.29$ & $9.88 \pm 0.18$ & $13.49 \pm 0.32$ & $47.42 \pm 1.09$ & $37.47 \pm 0.69$ & $46.65 \pm 1.09$ \\
\hline
\end{tabular}
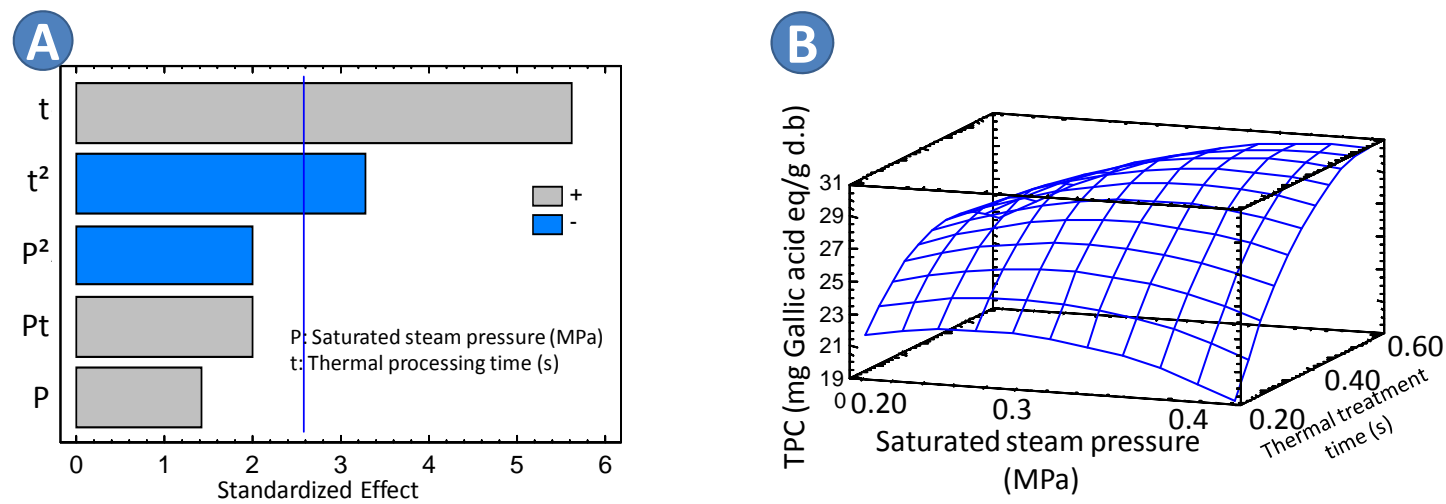

Figure 4. Effects of steam pressure (MPa) and holding time (s) of DIC-drying on the TPC of green poblano peppers. A: pareto chart and B: surface response plot.

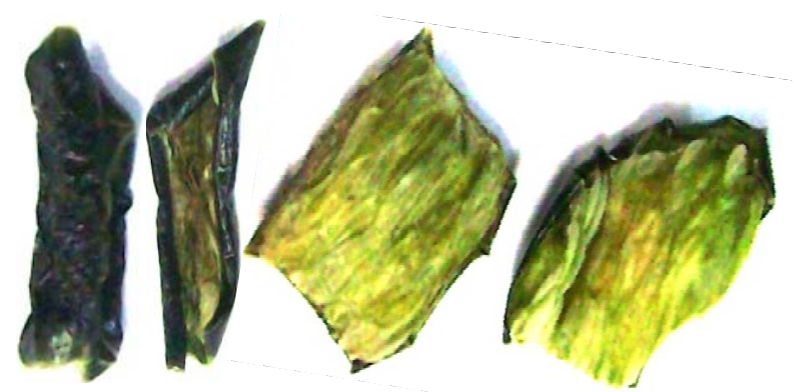

Figure 5. Poblano pepper dried by THAD (left) and DIC-D (right). DIC treatment conditions: $P=0.30 \mathrm{MPa}$ and $\mathrm{t}=60 \mathrm{~s}$.

drying process, THAD and DIC-D (P: $0.45 \mathrm{MPa}, \mathrm{t}: 40 \mathrm{~s})$, decreased the TFC respect to $\mathrm{RM}(11.86 \mathrm{mg}$ rutin equivalents/g d.b) by $7 \%$ and $12 \%$ respectively.

Therefore, it was observed that the flavonoid content of DIC-D largely changed according to DIC treatment conditions, with the thermal holding time " $\mathrm{t}$ " as the most responsible of this changes (Figure 6A); the higher the time, the higher the TFC. Else, as observed on Figure 6B, while pressure impact is negligible for low values of " $t$ ", the interaction of factors showed that high values of treatment time imply a positive impact of steam pressure on the TFC. The empirical regression model $\left(\mathrm{R}^{2}=\right.$ $82.33 \%$ ), Equation (2), allowed to determine the optimal operating conditions ( $\mathrm{P}: 0.45 \mathrm{MPa}, \mathrm{t}: 56 \mathrm{~s})$ to maximize the response (10.92 $\mathrm{mg}$ rutin equivalents/g d.b).

$$
\begin{aligned}
\text { TFC }_{\text {DIC-D }}= & 5.3546-12.4569 \mathrm{P}+0.2372 \mathrm{t} \\
& -2.2801 \mathrm{P}^{2}+0.39587 \mathrm{Pt}-0.0037 \mathrm{t}^{2}
\end{aligned}
$$

On the other side, FD and DIC-S (P: 0.45MPa, t: $40 \mathrm{~s}$ ) increased the TFC respect to RM, 1.20 times and 1.28 times respectively. Else, for DIC-S it was observed that both operating parameters: saturated steam pressure "P" 

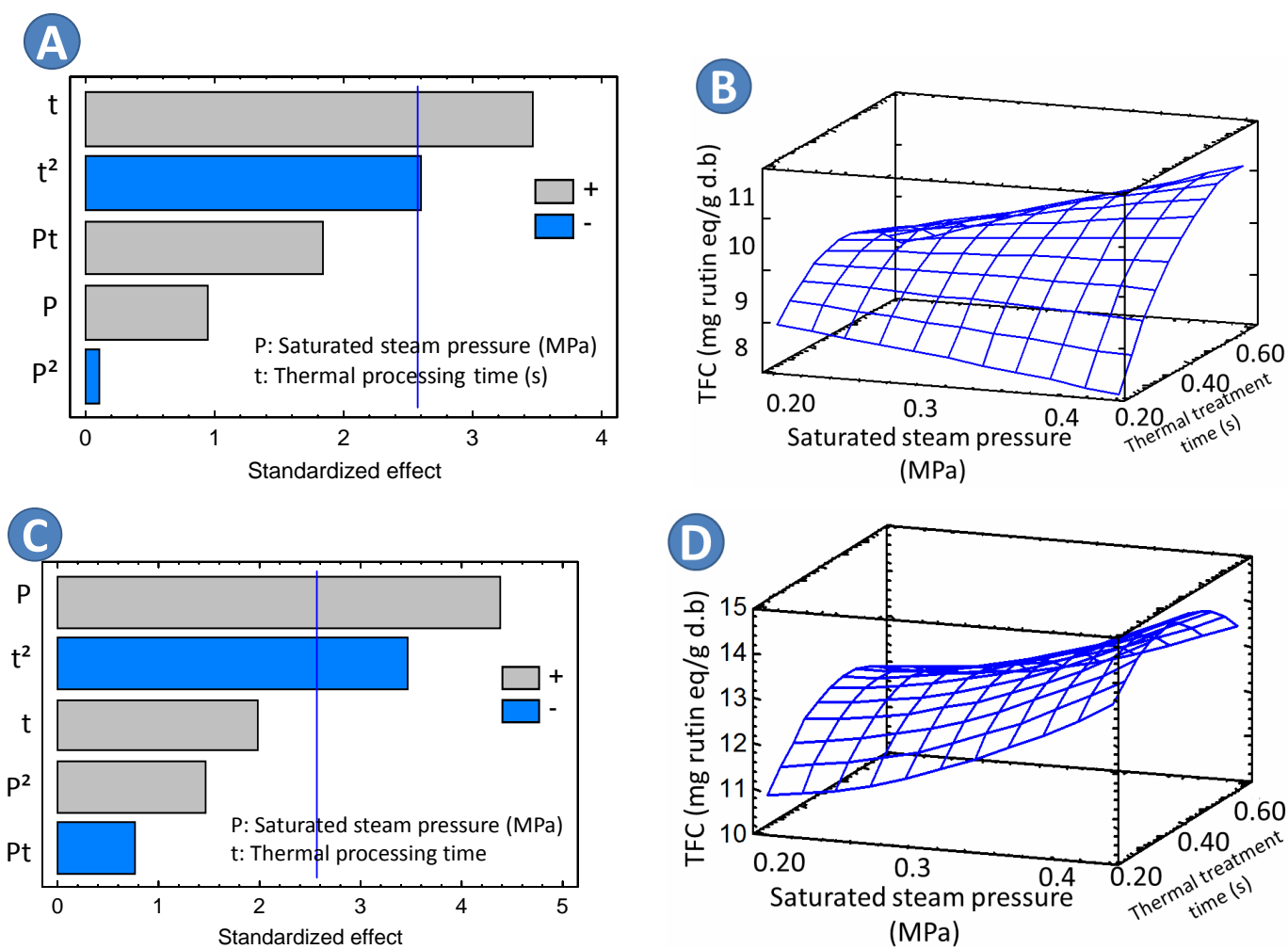

Figure 6. Effects of steam pressure (MPa) and holding time (s) of DIC treatment on the total flavonoids content of poblano peppers. A and B: DIC-dried (left-pareto chart and right—surface response plot); C and D: DIC-swelling (left-pareto chart and right-surface response).

and the thermal processing time " $t$ ", had significant effects on the TFC (Figure 6C). The higher the saturated steam pressure, the higher the TFC (Figure 6D). Statistical analysis of the experimental design allowed to obtain the prediction model $\left(\mathrm{R}^{2}=89.39 \%\right)$ for the TFC Equation (3) and the optimal operating conditions to maximize the response (P: $0.45 \mathrm{MPa}, \mathrm{t}: 40.3 \mathrm{~s}$ ) at $14.91 \mathrm{mg}$. rutin equivalents/g d.b.

$$
\begin{aligned}
\mathrm{TFC}_{\mathrm{DIC}-\mathrm{S}}= & 3.0600-3.9208 \mathrm{P}+0.4276 \mathrm{t} \\
& +30.1726 \mathrm{P}^{2}-0.14509 \mathrm{Pt}-0.0044 \mathrm{t}^{2}
\end{aligned}
$$

On the other hand, freezing conditions (TF and DIC-F) enhanced the preservation of TFC, being the DIC-F the best process, by increasing 1.34 times (P: $0.30 \mathrm{MPa}$, t: 20 s) the TFC respect to RM.

Furthermore, some research works had shown that the relation between total flavonoids and phenol content of peppers changed depending on variety and ripening stages $[33,36]$; however there is not much information about changes during processing. Regarding this aspect, to better understand the impact of the different studied drying and freezing treatments, the relation between the flavonoids and phenols was calculated by Equation (4):

$$
\text { RFP } \%=\frac{(\text { Total Flavonoids content of sample })}{(\text { Total Phenol content sample })}
$$

Hence, this study showed that fresh Poblano Pepper had a RFP of around $48 \%$, suggesting that flavonoids were the most important group of phenolic compounds of fresh fruit. Else, important changes on the RFP where found on the different preservation process (Tables 3 and 4).

For drying, two behaviors were founded. In the case of FD an increase on the RFP of 1.26 times respect to RM was founded. On the other hand, in the case of DIC-D and THAD, a decrease on the RFP compared to RM was founded, being this of $18.07 \%$ (P: $0.19 \mathrm{MPa}, \mathrm{t}: 26 \mathrm{~s}$ ) and $7.70 \%$, respectively. This behavior showed that these drying processes preserved other kind of phenolics better than flavonoids.

Particularly for DIC-D, it was founded that the thermal holding time was the most influencing parameter compared to the saturated steam pressure (Figure 7A). The lower the holding time, the higher the RFP. Else, under high values of steam saturated pressure, the RFP was increased (Figure 7B). Statistical analysis of the experimental design allowed to obtain the prediction model Equation (5) for the RFP $\left(\mathrm{R}^{2}=75.04 \%\right)$.

To maximize the RFP, the optimum conditions were P: $0.14 \mathrm{MPa}$ and t: 20 s. Optimal value: $42.99 \%$.

$$
\begin{aligned}
\% \mathrm{RFP}_{\text {DIC-D }}= & 61.15-95.8897 \mathrm{P}-0.44895 \mathrm{t} \\
& +157.959 \mathrm{P}^{2}-0.0622 \mathrm{Pt}+0.0040382 \mathrm{t}^{2}
\end{aligned}
$$



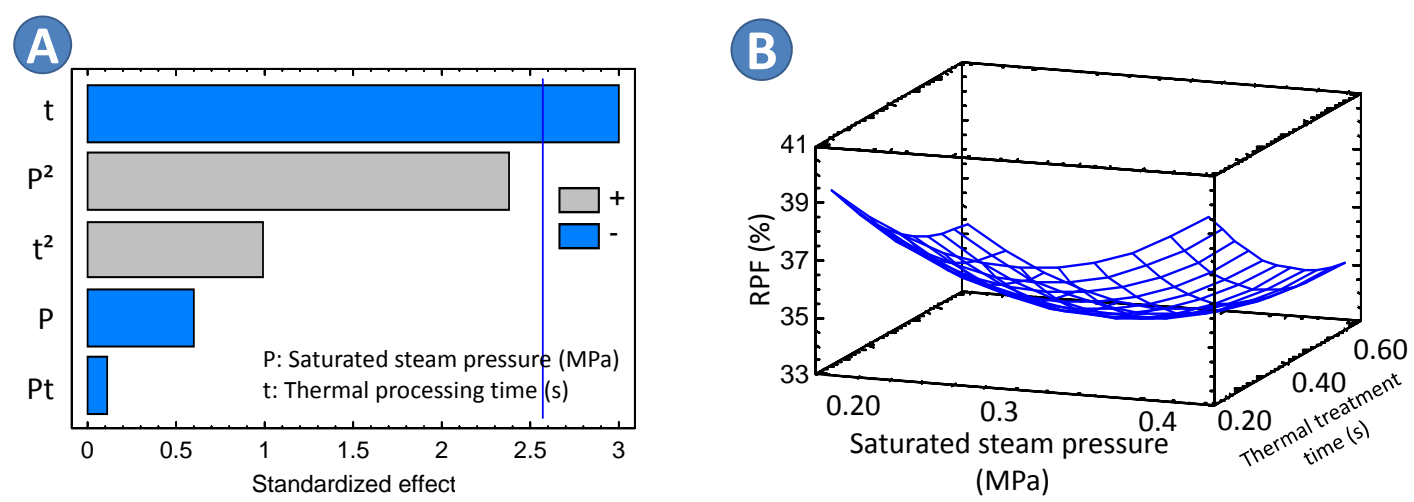

Figure 7. Effects of steam pressure (MPa) and holding time (s) of DIC-dried treatment on the RFP of green poblano peppers. A: pareto chart and B: surface response plot.

On the other hand, although under the selected range of DIC treatment conditions, any of the factors, "P" and " $t$ " presented significant effects on the RFP of DIC-F and DIC-S, the DIC treatment exhibited an interesting behavior on DIC-F (P: $0.30 \mathrm{MPa}, \mathrm{t}: 20 \mathrm{~s}$ ) and DIC-S (P: $0.30 \mathrm{MPa}$, t: $40 \mathrm{~s}$ ) compared to $\mathrm{RM}$, by raising it on 1.1 and 1.3 times respectively.

Finally, it has been found that frozen process preserved advantageously the RFP; being the TF the process that preserves better the RFP (86.89\%). Lower temperatures resulted in significantly better retention of flavonoids.

\subsection{Antiradical Activity by DPPH of Dried and Frozen Poblano Pepper}

In recent years the free radical scavenging activity (DPPH method) has been widely applied to estimate the antioxidant activity of different varieties of fresh pepper [29,31, $34,37,40]$, nevertheless few information exist about its changes by processing. In this study, to evaluate the impact of the different preserving process, the antiradical activity (ARA) was studied at 500 micromolar Gallic acid equivalents concentration of pepper extracts.

At this respect, results showed that fresh Poblano Pepper (RM) had an interesting antiradical activity, being this of $38.55 \%$ of DPPH discoloration (Table 5). This result could be related to the presence of high amounts of phenolic and flavonoid compounds on the extracts, and also to another compounds as capsaicinoids, carotenoids, ascorbic acid, etc. [31,40].

First of all, we highlight the absence of any correlation between ARA and TEAC, although both should reveal the antioxidant activity. This observation was done similarly by Celiktas et al., 2007 in their work concerning the Rosmarinus officinalis extracts [41], and by Ramdane and Mohan, 2004 [42] with their review on the correlation among different antioxidant assays.

Else, among the studied preserving process (Tables 5
Table 5. Antiradical activity by DPPH (ARA) and by trolox equivalent antioxidant capacity (TEAC) of dried and frozen poblano pepper (For both ARA and TEAC in terms of antioxidant activity, higher is better).

\begin{tabular}{ccc}
\hline Treatment & $\begin{array}{c}\text { ARA (\% of DPPH } \\
\text { Discoloration) }\end{array}$ & TEAC \\
\hline RM & $38.55 \pm 2.31$ & $143.42 \pm 4.58$ \\
FD & $43.91 \pm 6.10$ & $232.82 \pm 10.48$ \\
THAD & $27.70 \pm 2.88$ & $195.55 \pm 2.41$ \\
TF & $48.69 \pm 1.28$ & $101.61 \pm 7.57$ \\
\hline
\end{tabular}

Raw Material (RM), Freeze Drying (FD), Traditional Hot Air Drying (THAD), Traditional Freezing (TF) and Pre-drying (Pre-D) of Green Poblano Pepper. Values represent the mean of triplicates measures \pm the standard error.

and 6) the DIC-S (P: $0.41 \mathrm{MPa}$, t: $26 \mathrm{~s}$ ), THAD and DICF (P: $0.41, \mathrm{t}: 54 \mathrm{~s})$, reduced the ARA500 of peppers on $31.86 \%, 28.15 \%$ and $3.94 \%$ respectively compared to RM. In the case of DIC-S it was founded that the quadratic effect of steam pressure and the interaction between the pressure and time had a significant impact on the ARA (Figure 8A). In fact, higher values of holding time and steam pressure increased the ARA (Figure 8B). Statistical analysis of the experimental design allowed to obtain the prediction model Equation (6) for the ARA $\left(\mathrm{R}^{2}=85.16 \%\right)$. The optimum conditions to obtain $31.98 \%$ of ARA were calculated at P: $0.45 \mathrm{MPa}$ and $\mathrm{t}: 20.2 \mathrm{~s}$.

$$
\begin{aligned}
\text { ARA }_{500 \text { DIC }-\mathrm{s}}= & 23.0455-31.207 \mathrm{P}+0.01237 \mathrm{t} \\
& +168.313 \mathrm{P}^{2}-1.5224 \mathrm{Pt}+0.00487 \mathrm{t}^{2}
\end{aligned}
$$

For the DIC-F process, any of the studied DIC factors ( $\mathrm{P}$ and $\mathrm{t}$ ) presented a significant effect on the ARA. The highest value achieved in this range was obtained under P: $0.41 \mathrm{MPa}$ and Time: $54 \mathrm{~s}$ (37.03\% of DPPH discoloration), and the average of all treatments was of $31.70 \%$.

On the other hand, respect to RM, the DIC-D (P: 0.45 $\mathrm{MPa}, \mathrm{t}: 40 \mathrm{~s}$ ), FD and TF increased the ARA on 1.05, 1.13 and 1.26 times respectively. Under the selected 
Table 6. Antiradical activity by DPPH (ARA) and TEAC of dried and frozen poblano pepper couple to DIC.

\begin{tabular}{ccccccc}
\hline \multirow{2}{*}{ DIC \# } & \multicolumn{3}{c}{ ARA (\% of DPPH discoloration) } & \multicolumn{3}{c}{ TEAC } \\
\cline { 2 - 7 } & DIC-Swelling & DIC-Dried & DIC-Frozen & DIC-Swelling & DIC-Dried & DIC-Frozen \\
\hline 1 & $24.57 \pm 2.81$ & $40.69 \pm 1.08$ & $25.38 \pm 2.32$ & $98.58 \pm 7.06$ & $176.45 \pm 32.51$ & $265.85 \pm 6.70$ \\
2 & $21.31 \pm 0.54$ & $12.43 \pm 1.02$ & $23.28 \pm 2.20$ & $223.42 \pm 4.10$ & $171.61 \pm 11.44$ & $238.88 \pm 7.84$ \\
3 & $19.97 \pm 2.26$ & $16.58 \pm 1.78$ & $30.87 \pm 1.42$ & $116.45 \pm 3.96$ & $172.82 \pm 17.56$ & $291.61 \pm 41.16$ \\
4 & $18.59 \pm 0.31$ & $18.10 \pm 2.48$ & $37.03 \pm 1.86$ & $247.67 \pm 20.33$ & $241.91 \pm 28.39$ & $209.79 \pm 13.31$ \\
5 & $26.27 \pm 4.16$ & $16.58 \pm 4.76$ & $38.10 \pm 1.52$ & $233.42 \pm 7.62$ & $130.70 \pm 33.73$ & $314.33 \pm 16.87$ \\
6 & $17.83 \pm 5.03$ & $14.66 \pm 2.32$ & $25.15 \pm 1.55$ & $205.55 \pm 28.65$ & $155.85 \pm 9.64$ & $298.88 \pm 33.41$ \\
7 & $19.12 \pm 3.10$ & $27.79 \pm 3.61$ & $33.91 \pm 2.28$ & $243.12 \pm 23.99$ & $193.42 \pm 8.59$ & $365.24 \pm 13.89$ \\
8 & $20.82 \pm 1.07$ & $17.83 \pm 1.34$ & $29.44 \pm 3.12$ & $252.52 \pm 13.49$ & $141.00 \pm 5.68$ & $331.00 \pm 15.53$ \\
9 & $22.52 \pm 0.15$ & $17.65 \pm 2.48$ & $34.93 \pm 2.10$ & $242.52 \pm 5.33$ & $157.97 \pm 3.44$ & $414.64 \pm 25.50$ \\
10 & $21.45 \pm 1.70$ & $26.31 \pm 1.23$ & $35.11 \pm 2.69$ & $254.03 \pm 16.07$ & $234.03 \pm 26.60$ & $244.64 \pm 5.96$ \\
11 & $18.72 \pm 1.12$ & $13.54 \pm 1.21$ & $35.56 \pm 4.65$ & $145.55 \pm 12.82$ & $163.73 \pm 11.82$ & $352.52 \pm 33.64$ \\
\hline
\end{tabular}

Values represent the mean of triplicates \pm the standard error.
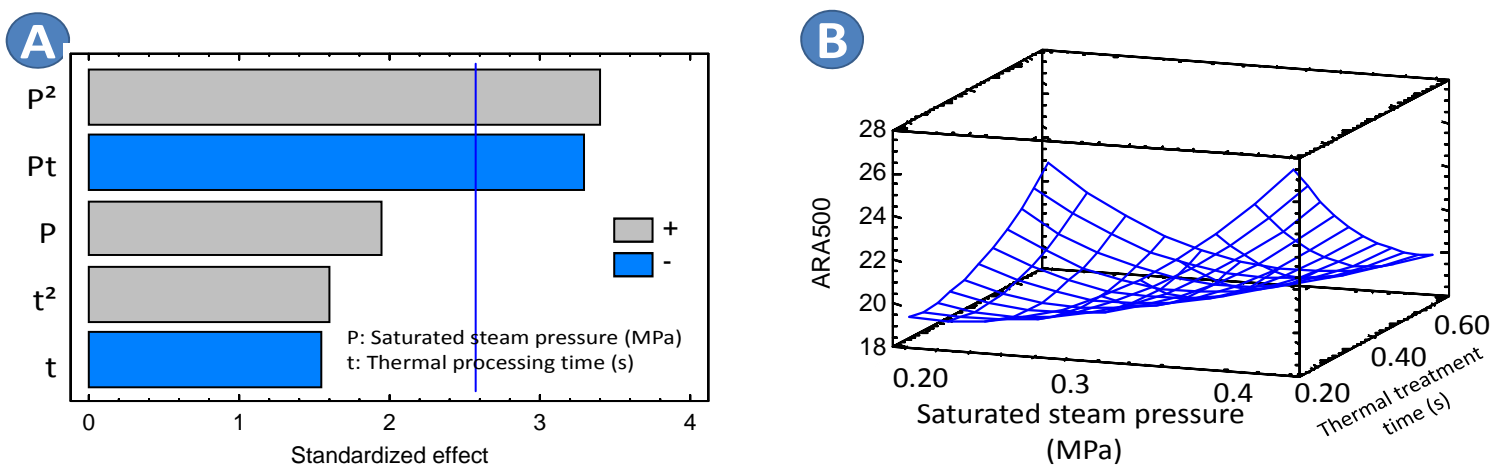

Figure 8. Effects of steam pressure (MPa) and holding time (s) of DIC treatment on the ARA of green poblano peppers extracts at $500 \mu \mathrm{M}$ equivalents of gallic acid. A and B: DIC-swelling (left-pareto chart and right-surface response plot).

range of DIC-D treatment conditions ( $\mathrm{P}$ and $\mathrm{t}$ ) an insignificant effect on the ARA was presented; nonetheless higher values were reached in two cases: at low values of pressure and time and at high levels of pressure and time. The highest value achieved in this range was obtained under $0.45 \mathrm{MPa}$ and $40 \mathrm{~s}$ as time, with $40.69 \%$ of discoloration. The ARA average of all treatments was $20.19 \%$.

Finally, by analyzing the Pareto Chart of DIC-S and the results of the DIC-D and DIC-F, it is clearly noted that according to selected parameters of the DIC treatment and the second assisted process, the ARA of samples can be optimized.

\subsection{Trolox Equivalent Antioxidant Capacity by ABTS of Dried and Frozen Poblano Pepper}

To further understand the effect of the different studied preserving process on the antioxidant activity of dried and frozen peppers, the Trolox Equivalent Antioxidant Capacity (TEAC) assay was also evaluated; samples with high TEAC values have been considered a good antioxi- dant activity.Hence, as showed on Table 5, for the RM the TEAC was 143.42, meaning that even if the antioxidant capacity of fresh pepper extract was good, the antioxidant capacity was only $28.68 \%$ of that of Trolox solution at the same concentration. Concerning the impact of preserving process on TEAC, results showed an increasing on the antioxidant activity respect to RM for THAD (1.36 times), FD (1.62 times), DIC-D (1.69 times, P: 0.41 MPa, t: $54 \mathrm{~s})$, DIC-S (1.77 times, P: $0.30 \mathrm{MPa}, \mathrm{t}: 20 \mathrm{~s})$ and DIC-F (2.89 times, P: $0.15 \mathrm{MPa}, \mathrm{t}: 40 \mathrm{~s}$ ).

Particularly for DIC-D the steam pressure (P) had negative impact for the lowest holding time $(\mathrm{t})$ value; and positive effect for the highest holding time $(\mathrm{t})$ value (Figure 9A). High values of TEAC could be reached at the highest values of both steam pressure and holding time (Figure 9B). Statistical analysis of the experimental design allowed to getting a prediction model Equation (7) for the TEAC $\left(\mathrm{R}^{2}=75.39 \%\right)$ and calculating the optimal conditions of treatment as $\mathrm{P}=0.45 \mathrm{MPa}$ and $\mathrm{t}=59.79 \mathrm{~s}$; with an optimal value of 285.62 TEAC. 

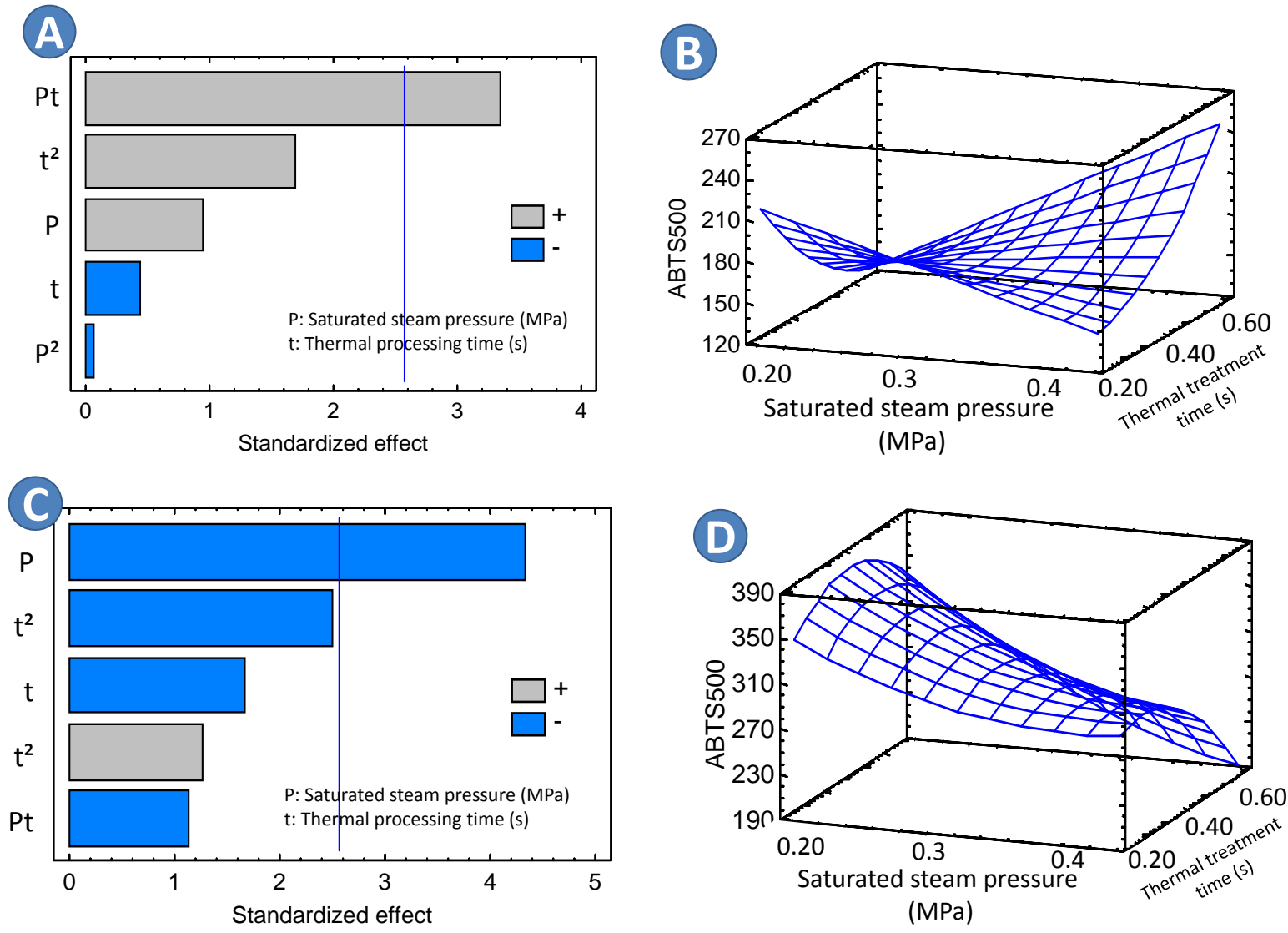

Figure 9. Effects of steam pressure (MPa) and holding time (s) of DIC treatment on the TEAC of green poblano peppers extracts at $500 \mu \mathrm{M}$ equivalents of gallic acid. A and B: DIC-Dried (Left-Pareto Chart and Right-Surface Response Plot); C and D: DIC-Frozen (Left-Pareto Chart and Right-Surface Response Plot).

$$
\begin{aligned}
\text { TEAC }_{\text {DIC-D }}= & 608.664-963.495 \mathrm{P}-15.2853 \mathrm{t} \\
& -43.3062 \mathrm{P}^{2}+26.5643 \mathrm{Pt}+0.08816 \mathrm{t}^{2}
\end{aligned}
$$

In the case of DIC-F, the steam pressure showed a significant impact on the TEAC (Figure 9C). The lower the steam pressure, the higher the TEAC (Figure 9D). Statistical analysis of the experimental design led to obtain an empirical prediction model Equation (8) for the TEAC $\left(\mathrm{R}^{2}=86.83 \%\right)$ and allowed to calculating the optimal operation conditions at $\mathrm{P}=0.14 \mathrm{MPa}$ and $\mathrm{t}=41 \mathrm{~s}$; with an optimal value of 415.23 TEAC. It was the best process to increase the TEAC, having almost the same antioxidant activity as Trolox.

$$
\begin{aligned}
\text { TEAC }_{\text {DIC-F }}= & 215.354-795.251 \mathrm{P}+15.4855 \mathrm{t} \\
& +1361.77 \mathrm{P}^{2}-11.4128 \mathrm{Pt}-0.1672 \mathrm{t}^{2}
\end{aligned}
$$

On the other side, for DIC-S at selected range of DIC treatment, factors "P" and " $\mathrm{t}$ " presented a negligible effect on TEAC. The highest value of $254.03 \%$ was obtained under P: $0.30 \mathrm{MPa}$ and t: $20 \mathrm{~s}$. Opposite results were founded for TF, which reduced on $29 \%$ the TEAC respect to RM. Overall, among the studied treatments, results showed that by selecting the optimum parameters conditions of DIC treatment, the antioxidant capacity could be substantially improved.

\section{Discussion}

The impact of the different preserving methods on the phytochemical content and antioxidant activity of Poblano Pepper could be linked to many reasons.

In the case of freeze dried samples, the reduction of the TPC should be related to the large surface area exposed during processing, which more prone the phytochemicals degradation [43], and to the incapacity of the process to inactivate the enzymes that causes degradation of the phenolics compounds. On the other hand, the increase of the TFC should be related to the structure alteration of the tissue, which made easier the flavonoids extraction, particularly of those more non-polar [44]. The increase of the RFP, reaffirmed that this process favored the preservation of the pepper flavonoids respect to the rest of phenolic compounds; similar results were founded on freeze dried onion [44]. Regarding the antiradical activity of FD samples, the increase of the ARA and TEAC should be related to the increase of their total flavonoids 
content. Shofian et al., 2011, showed a good preservation of heat-sensitive antioxidant components by the FD process [45].

For the THAD samples, the minimal increase of TPC should be related to the intensification of drying conditions (low temperature, high air flux and low relative humidity of the air). Respect to the TFC, the decrease could be related to the destruction by oxidation of some flavonoids during the long-time of drying [46]. The decrease of the RFP showed that the THAD process preserved better other kind of phenolics than flavonoids. Regarding the antiradical activity, the decrease of ARA possibly should be related to a reduction on its TFC. The ARA of total dried Korean peppers was also affected by air drying conditions [3]. For TEAC, the increase could be related to the nature of the assay and to the preservation of the total phenolic content of the extracts.

For traditional freezing samples, the loss of TPC could be linked to oxidative enzyme reactions during the storage [47]. Else, the preservation of the TFC should be related to the tolerance of these molecules to freezing temperatures. The TFC of Brussels sprouts were also well preserved under freezing conditions [48]. Furthermore, the increase of the RFP showed that this process favored the preservation of the pepper flavonoids respect to other phenolic compounds. Moreover, among all the studied preserving methods, the TF was the best method to increase the ARA; this should be due to flavonoids were the main responsible of antiradical activity of pepper and this process preserved quite well these bioactive compounds. The reduction of the TEAC would be linked to the reduction on the TPC of the samples.

In the case of the impact of the DIC treatment, the improvement of the TPC (DIC-S, DIC-D and DIC-F), the TFC (DIC-S and DIC-F), the ARA (DIC-D) and the TEAC (DIC-S, DIC-D and DIC-F) could be attributed to the new generated food matrix structure, which was expanded during DIC thermal-mechanical treatment, allowing bioactive compounds to be more available, favoring their extraction. The increasing of micro-alveolation in the food matrix possibly favors the internal diffusion of bioactive molecules. Therefore, in the specific case of phenolic compounds, it could be possible that the inactivation of the polyphenol oxidase enzyme that occurs during heating in the cooking process would also occur during the DIC process, avoiding the degradation of polyphenols [49,50]. Additionally, high temperatures (i.e. $>90^{\circ} \mathrm{C}$ ) would cause the formation of phenolic compounds because of the availability of precursors of phenolic molecules by non-enzymatic inter-conversion between phenolic molecules [51].

Else, for the DIC-F the improvement of the TPC and TFC would be also attributed to the reduction of moisture content before freezing, which reduces the cell wall damage, caused by traditional freezing. The study of Mounir et al., 2011 [52], also showed more available flavonoids after the DIC treatment of apples.

The decrease of the TFC and the RFP of the DIC-D should be due to the fact that some flavonoids were destroyed by oxidation during the second drying [53].

Furthermore, the increase of the RPF of the DIC-S and the DIC-F would be related to the stabilization of pepper flavonoid compounds during the DIC treatment. At this respect, the study of Adamczak, 2009 [54], indicates that drying temperatures in the order of $120^{\circ} \mathrm{C}-150^{\circ} \mathrm{C}$, stabilizes better flavonoid compounds than a temperature of $40^{\circ} \mathrm{C}-60^{\circ} \mathrm{C}$.

Moreover, in the case of ARA, its increase on DIC-D samples should be also related to the synthesis of new molecules with antioxidant activity during the DIC treatment; asMaillard derived melanoidins which have been shown a varying degree of antioxidant activity [51]. Else, other studies on peppers showed that boiling, steaming $[50,55,56]$ and drying at high temperatures (i.e. $>90^{\circ} \mathrm{C}$ ) $[14,57]$ also increased the ARA. Opposite, the reduction of ARA on the DIC-F and DIC-S samples, would be related to the changes of composition of their bioactive molecules during storage.

According to the different obtained results from DIC samples it has been highlighted the importance of ulterior conditions of processing after DIC treatment to preserve the bioactive compounds and to enhance the antioxidant activity.

Therefore, even that ARA and TEAC assays were based on similar redox reactions, the differences among the obtained results would be related to their particular limits of applications [58]. In this study, the use of methanol solvent possibly restricted the cellular compounds responsible for scavenge the DPPH radical, then only methanolic soluble molecules, would have been involved in this scavenging process [59].

\section{Conclusion}

The present work allowed us to study different food operations assisted by instant controlled pressure drop DIC treatment. The use of DIC as intensifying process had a direct impact on active molecules and functional activity in the case of Green "Poblano" Pepper (Capsicum annuum L.). Results issued from DIC-assisted hot air drying, and DIC-assisted freezing allowed identifying the most important factor in terms of DIC operating parameters. Hence, the saturated steam pressure and the processing time could normally be recognized to obtain the best DIC treatment depending of the considered food operation.

\section{Acknowledgements}

The authors acknowledge the ConsejoNacional de Ciencia 
y Tecnología (CONACyT-Mexico) and the Programme de Coopération Post-Gradué Franco-Mexicain (PCP) for the financial support given to this research. Also we wish to thank ABCAR-DIC PROCESS SAS (La Rochelle, France) for providing drier equipment and pilot-scale DIC reactor.

\section{REFERENCES}

[1] B. Pickersgill, "Peppers and Chillies," In: C. Benjamin, Ed., Encyclopedia of Food Sciences and Nutrition, Academic Press, Oxford, 2003, pp. 4460-4467. doi:10.1016/B0-12-227055-X/00904-4

[2] O. Cisneros-Pineda, et al., "Capsaicinoids Quantification in Chili Peppers Cultivated in the State of Yucatan, Mexico," Food Chemistry, Vol. 104, No. 4, 2007, pp. 17551760. doi:10.1016/j.foodchem.2006.10.076

[3] K. Suna, et al., "Effect of Drying in Antioxidant Activity and Changes of Ascorbic Acid and Colour by Different Drying and Storage in Korean Red Pepper (Capsicum annuum, L.)," International Journal of Food Science \& Technology, Vol. 41, No. S1, 2006, pp. 90-95. doi:10.1111/j.1365-2621.2006.01349.x

[4] M.-R. Kim, et al., "Capsaicin Prevents Ethanol-Induced Teratogenicity in Cultured Mouse Whole Embryos," Reproductive Toxicology, Vol. 26, No. 3-4, 2008, pp. 292297. doi:10.1016/j.reprotox.2008.09.006

[5] S. Malagarie-Cazenave, et al., "Capsaicin, a Component of Red Peppers, Induces Expression of Androgen Receptor via PI3K and MAPK Pathways in Prostate LNCaP Cells," FEBS Letters, Vol. 583, No. 1, 2009, pp. 141-147. doi:10.1016/j.febslet.2008.11.038

[6] G. Yaldiz, M. Ozguven and N. Sekeroglu, "Variation in Capsaicin Contents of Different Capsicum Species and Lines by Varying Drying Parameters," Industrial Crops and Products, Vol. 32, No. 3, 2010, pp. 434-438. doi:10.1016/j.indcrop.2010.06.013

[7] B. J. Xu and S. K. C. Chang, "Effect of Soaking, Boiling, and Steaming on Total Phenolic Content and Antioxidant Activities of Cool Season Food Legumes," Food Chemistry, Vol. 110, No. 1, 2008, pp. 1-13. doi:10.1016/j.foodchem.2008.01.045

[8] R. K. Toor and G. P. Savage, "Effect of Semi-Drying on the Antioxidant Components of Tomatoes," Food Chemistry, Vol. 94, No. 1, 2006, pp. 90-97. doi:10.1016/j.foodchem.2004.10.054

[9] S. Veillet, J. Busch and G. Savage, "Acceptability and Antioxidant Properties of a Semi-Dried and Smoked Tomato Product," Journal of Food Agriculture \& Environment, Vol. 7, No. 2, 2009, pp. 70-75.

[10] A. M. Chuah, et al., "Effect of Cooking on the Antioxidant Properties of Coloured Peppers," Food Chemistry, Vol. 111, No. 1, 2008, pp. 20-28. doi:10.1016/j.foodchem.2008.03.022

[11] J. K. Willcox, S. L. Ash and G. L. Catignani, "Antioxidants and Prevention of Chronic Disease," Critical Reviews in Food Science \& Nutrition, Vol. 44, No. 4, 2004,

\section{pp. 275-295. doi:10.1080/10408690490468489}

[12] L. R. Howard and C. Hernandez-Brenes, "Antioxidant Content and Market Quality of Jalapeno Pepper Rings as Affected by Minimal Processing and Modified Atmosphere Packaging," Journal of Food Quality, Vol. 21, No. 4, 1998, pp. 317-327. doi:10.1111/j.1745-4557.1998.tb00525.x

[13] C. Ratti, et al., "Drying of Garlic (Allium sativum) and Its Effect on Allicin Retention," Drying Technology, Vol. 25, No. 2, 2007, pp. 349-356. doi: $10.1080 / 07373930601120100$

[14] A. Vega-Galvez, et al., "Effect of Air-Drying Temperature on Physico-Chemical Properties, Antioxidant Capacity, Colour and Total Phenolic Content of Red Pepper (Capsicum annuum L. var. Hungarian)," Food Chemistry, Vol. 117, No. 4, 2009, pp. 647-653. doi:10.1016/j.foodchem.2009.04.066

[15] E. K. Dermesonlouoglou, M. C. Giannakourou and P. Taoukis, "Stability of Dehydrofrozen Tomatoes Pretreated with Alternative Osmotic Solutes," Journal of Food Engineering, Vol. 78, No. 1, 2007, pp. 272-280. doi:10.1016/j.jfoodeng.2005.09.026

[16] C. Ilicali and F. Icier, "Freezing Time Prediction for Partially Dried Papaya Puree with Infinite Cylinder Geometry," Journal of Food Engineering, Vol. 100, No. 4, 2010, pp. 696-704. doi:10.1016/j.jfoodeng.2010.05.022

[17] S. A. Rezzoug, et al., "Effect of Instantaneous Controlled Pressure Drop Process on the Hydration Capacity of Scleroglucan: Optimisation of Operating Conditions by Response Surface Methodology," Carbohydrate Polymers, Vol. 42, No. 1, 2000, pp. 73-84. doi:10.1016/S0144-8617(99)00122-8

[18] B. B. Amor, et al., "Effect of Instant Controlled Pressure Drop Treatments on the Oligosaccharides Extractability and Microstructure of Tephrosia purpurea Seeds," Journal of Chromatography A, Vol. 1213, No. 2, 2008, pp. 118-124. doi:10.1016/j.chroma.2008.10.065

[19] I. M. Kamal, et al., "Structure Expansion of Green Coffee Beans Using Instantaneous Controlled Pressure Drop Process," Innovative Food Science \& Emerging Technologies, Vol. 9, No. 4, 2008, pp. 534-541. doi:10.1016/j.ifset.2008.01.004

[20] AOAC, "Official Methods of Analysis of AOAC (Association of Official Analytical Chemists) International (CD-ROM)," AOAC International, Gaithersburg, 1996.

[21] S. S. Nielsen, "Food Analysis Laboratory Manual," Kluwer Academic/Plenum Publishers, New York, 2003.

[22] A. Cardador-Martinez, G. Loarca-Pina and B. D. Oomah, "Antioxidant activity in common beans (Phaseolus vulgaris L.)," Journal of Agricultural and Food Chemistry, Vol. 50, No. 24, 2002, pp. 6975-6980. doi:10.1021/jf020296n

[23] V. L. Singleton and J. A. Rossi Jr., "Colorimetry of Total Phenolics with Phosphomolybdic-Phosphotungstic Acid Reagents," American Journal of Enology Viticulture, Vol. 16, No. 3, 1965, pp. 144-158.

[24] B. D. Oomah, A. Cardador-Martínez and G. Loarca-Piña, 
"Phenolics and Antioxidative Activities in Common Beans (Phaseolus vulgaris L.)," Journal of the Science of Food and Agriculture, Vol. 85, No. 6, 2005, pp. 935-942. doi:10.1002/jsfa.2019

[25] R. Re, et al., "Antioxidant Activity Applying an Improved ABTS Radical Cation Decolorization Assay," Free Radical Biology and Medicine, Vol. 26, No. 9-10, 1999, pp. 1231-1237. doi:10.1016/S0891-5849(98)00315-3

[26] N. Albitar, et al., "Improving the Drying of Onion Using the Instant Controlled Pressure Drop Technology," Drying Technology, Vol. 29, No. 9, 2011, pp. 993-1001. doi:10.1080/07373937.2010.507912

[27] D. T. Cong, et al., "Dehydration by Successive Pressure Drops for Drying Paddy Rice Treated by Instant Controlled Pressure Drop," Drying Technology, Vol. 26, No. 4, 2008, pp. 443-451. doi:10.1080/07373930801929300

[28] J. M. F. Faustino, M. J. Barroca and R. P. F. Guiné, "Study of the Drying Kinetics of Green Bell Pepper and Chemical Characterization," Food and Bioproducts Processing, Vol. 85, No. 3, 2007, pp. 163-170. doi:10.1205/fbp07009

[29] N. Deepa, et al., "Antioxidant Activity in Some Red Sweet Pepper Cultivars," Journal of Food Composition and Analysis, Vol. 19, No. 6-7, 2006, pp. 572-578. doi:10.1016/j.jfca.2005.03.005

[30] G. F. Antonious, et al., "Antioxidants in Hot Pepper: Variation among Accessions," Journal of Environmental Science and Health Part B: Pesticides, Food Contaminants and Agricultural Wastes, Vol. 41, No. 7, 2006, pp. 1237-1243. doi:10.1080/03601230600857114

[31] M. Materska and I. Perucka, "Antioxidant Activity of the Main Phenolic Compounds Isolated from Hot Pepper Fruit (Capsicum annuum L.)," Journal of Agricultural and Food Chemistry, Vol. 53, No. 5, 2005, pp. 1750-1756. doi:10.1021/jf035331k

[32] M. Serrano, et al., "Antioxidant and Nutritive Constituents during Sweet Pepper Development and Ripening Are Enhanced by Nitrophenolate Treatments," Food Chemistry, Vol. 118, No. 3, 2010, pp. 497-503. doi:10.1016/j.foodchem.2009.05.006

[33] L. R. Howard, et al., "Changes in Phytochemical and Antioxidant Activity of Selected Pepper Cultivars (Capsicum Species) As Influenced by Maturity," Journal of Agricultural and Food Chemistry, Vol. 48, No. 5, 2000, pp. 1713-1720. doi:10.1021/jf990916t

[34] F. Menichini, et al., "The Influence of Fruit Ripening on the Phytochemical Content and Biological Activity of Capsicum chinense Jacq. cv Habanero," Food Chemistry, Vol. 114, No. 2, 2009, pp. 553-560. doi:10.1016/j.foodchem.2008.09.086

[35] J. M. Navarro, et al., "Changes in the Contents of Antioxidant Compounds in Pepper Fruits at Different Ripening Stages, as Affected by Salinity," Food Chemistry, Vol. 96, No. 1, 2006, pp. 66-73. doi:10.1016/j.foodchem.2005.01.057

[36] A. W. Chassy, et al., "Three-Year Comparison of the Content of Antioxidant Microconstituents and Several Quality Characteristics in Organic and Conventionally
Managed Tomatoes and Bell Peppers," Journal of Agricultural and Food Chemistry, Vol. 54, No. 21, 2006, pp. 8244-8252. doi:10.1021/if060950p

[37] M. Ghasemnezhad, M. Sherafati and G. A. Payvast, "Variation in Phenolic Compounds, Ascorbic Acid and Antioxidant Activity of Five Coloured Bell Pepper (Capsicum annuum) Fruits at Two Different Harvest Times," Journal of Functional Foods, Vol. 3, No. 1, 2011, pp. 4449. doi:10.1016/j.jff.2011.02.002

[38] M. Materska, et al., "Isolation and Structure Elucidation of Flavonoid and Phenolic Acid Glycosides from Pericarp of Hot Pepper Fruit Capsicum annuum L.," Phytochemistry, Vol. 63, No. 8, 2003, pp. 893-898. doi:10.1016/S0031-9422(03)00282-6

[39] J. Peterson and J. Dwyer, "Flavonoids: Dietary Occurrence and Biochemical Activity," Nutrition Research, Vol. 18, No. 12, 1998, pp. 1995-2018. doi:10.1016/S0271-5317(98)00169-9

[40] H. Matsufuji, et al., "Anti-Oxidant Content of Different Coloured Sweet Peppers, White, Green, Yellow, Orange and Red (Capsicum annuum L.)," International Journal of Food Science \& Technology, Vol. 42, No. 12, 2007, pp. 1482-1488. doi:10.1111/j.1365-2621.2006.01368.x

[41] O. Y. Celiktas, E. Bedir and F. V. Sukan, "In Vitro Antioxidant Activities of Rosmarinus officinalis Extracts Treated with Supercritical Carbon Dioxide," Food Chemistry, Vol. 101, No. 4, 2007, pp. 1457-1464. doi:10.1016/j.foodchem.2006.03.055

[42] D. Ramdane and J. S. Mohan, "Production Practices and Quality Assessment of Food Crops 4 Volumes: Vol. 3. Quality Handling and Evaluation," Kluwer Academic Publishers, Dordrecht, 2004.

[43] S. Y. Leong and I. Oey, "Effects of Processing on Anthocyanins, Carotenoids and Vitamin $\mathrm{C}$ in Summer Fruits and Vegetables," Food Chemistry, Vol. 133, No. 4, 2012, pp. 1577-1587. doi:10.1016/j.foodchem.2012.02.052

[44] M. R. Pérez-Gregorio, et al., "Changes in Antioxidant Flavonoids during Freeze-Drying of Red Onions and Subsequent Storage," Food Control, Vol. 22, No. 7, 2011, pp. 1108-1113. doi:10.1016/j.foodcont.2011.01.006

[45] N. M. Shofian, et al., "Effect of Freeze-Drying on the Antioxidant Compounds and Antioxidant Activity of Selected Tropical Fruits," International Journal of Molecular Sciences, Vol. 12, No. 7, 2011, pp. 4678-4692. doi:10.3390/ijms12074678

[46] C.-H. Zhou, et al., "Effects of Drying Methods on the Bioactive Components in Loquat (Eriobotrya japonica Lindl.) Flowers," Journal of Medicinal Plants Research, Vol. 5, No. 14, 2011, pp. 3037-3041.

[47] H. S. Lee and G. A. Coates, "Vitamin C in Frozen, Fresh Squeezed, Unpasteurized, Polyethylene-Bottled Orange Juice: A Storage Study," Food Chemistry, Vol. 65, No. 2, 1999, pp. 165-168. doi:10.1016/S0308-8146(98)00180-0

[48] D. F. Olivera, et al., "Effect of Blanching on the Quality of Brussels sprouts (Brassica oleracea L. gemmifera DC) after Frozen Storage," Journal of Food Engineering, Vol. 84 , No. 1, 2008, pp. 148-155.

doi:10.1016/j.jfoodeng.2007.05.005 
[49] T. Yamaguchi, et al., "Influence of Polyphenol and Ascorbate Oxidases during Cooking Process on the RadicalScavenging Activity of Vegetables," Food Science and Technology Research, Vol. 9, No. 1, 2003, pp. 79-83. doi: $10.3136 /$ fstr.9.79

[50] N. Turkmen, F. Sari and Y. S. Velioglu, "The Effect of Cooking Methods on Total Phenolics and Antioxidant Activity of Selected Green Vegetables," Food Chemistry, Vol. 93, No. 4, 2005, pp. 713-718. doi:10.1016/j.foodchem.2004.12.038

[51] F. Que, et al., "Comparison of Hot Air-Drying and FreezeDrying on the Physicochemical Properties and Antioxidant Activities of Pumpkin (Cucurbita moschata Duch.) flours. International Journal of Food Science \& Technology, Vol. 43, No. 7, 2008, pp. 1195-1201. doi:10.1111/j.1365-2621.2007.01590.x

[52] S. Mounir, et al., "Study of Instant Controlled Pressure Drop DIC Treatment in Manufacturing Snack and Expanded Granule Powder of Apple and Onion," Drying Technology, Vol. 29, No. 3, 2011, pp. 331-341. doi:10.1080/07373937.2010.491585

[53] I. Ioannou and M. Ghoul, "Biological Activities and Effects of Food Processing on Flavonoids as Phenolic Antioxidants," In: M. Petre, Ed., Advances in Applied Biotechnology, InTech, Rijeka, 2012.

[54] A. Adamczak, W. Buchwald and S. M. Kozlowski, "The Effect of Thermal and Freeze Drying on the Content of
Organic Acids and Flavonoids in Fruit of European Cranberry (Oxycoccus palustris Pers.)," Herba Polonica, Vol. 55, No. 3, 2009, pp. 94-102.

[55] C. W. Rico, et al., "The Comparative Effect of Steaming and Irradiation on the Physicochemical and Microbiological Properties of Dried Red Pepper (Capsicum annum L.)," Food Chemistry, Vol. 119, No. 3, 2010, pp. 1012-1016. doi:10.1016/i.foodchem.2009.08.005

[56] S. Shobana and K. A. Naidu, "Antioxidant Activity of Selected Indian Spices," Prostaglandins, Leukotrienes and Essential Fatty Acids, Vol. 62, No. 2, 2000, pp. 107110. doi:10.1054/plef.1999.0128

[57] D. Arslan and M. M. Özcan, "Dehydration of Red BellPepper (Capsicum annuum L.): Change in Drying Behavior, Colour and Antioxidant Content," Food and Bioproducts Processing, Vol. 89, No. 4, 2011, pp. 504-513. doi:10.1016/j.fbp.2010.09.009

[58] D. Huang, B. Ou and R. L. Prior, "The Chemistry behind Antioxidant Capacity Assays," Journal of Agricultural and Food Chemistry, Vol. 53, No. 6, 2005, pp. 1841-1856. doi:10.1021/jf030723c

[59] K. Marxen, et al., "Determination of DPPH Radical Oxidation Caused by Methanolic Extracts of Some Microalgal Species by Linear Regression Analysis of Spectrophotometric Measurements," Sensors, Vol. 7, No. 10, 2007, pp. 2080-2095. doi:10.3390/s7102080 